country and valley-bottom folds. There wore certainly several separate episodes of permafrost and at each it may be argued that the mean temperature was depressed by $13^{\circ} \mathrm{C}$ or more.

A chemical method for evaluating temperature and humidity is provided by weathered soils (not common in Britain). In the Atlantic, Emiliani's work on the oxygen isotope ratios of foraminifera tests in deep sea cores suggests a damped down version of the more violent fluctuations on land, with an extreme variation of the annual mean of about $6^{\circ} \mathrm{C}$.

The record of vegetational changes is of great importance and can be related to the physical conditions governing such features as the tree line, and the occurrence of the mixed oak forest. Some plants, like the holly and ivy, are indicators of winters which seldom went below freezing point.

Among vertebrate fossils, the musk ox, reindeer, arctic fox, lemming and a few others allow comparison with the arctic or sub-aretic, while hippopotamus and the fallow deer are equally indicative of mild conditions. Some extinct animals can now also be clearly related to cold or milder climatic conditions as well as to habitats, though exact estimations of climatic parameters are difficult.

The growing study of beetles is providing an everincreasing number of opportunities of estimating climate as well as ecology. An assemblage of beetles can sometimes be placed closely within the series of plant zones which occur above and below the tree line; and these can again be translated into physical terms of temperature, particularly summer ones. In four English examples, all chosen from interstadials of the Last Glaciation and with ages ranging from 57,000 to 13,600 years, it is argued that the summer temperature was as little as $22_{2}^{\circ}$ and as much as $5 \frac{1}{2}^{\circ}$ below the present day.

\section{FRONTIERS OF KNOWLEDGE IN THE STUDY OF SENSORY FUNCTION}

$I^{\mathrm{s}}$ $\mathrm{N}$ his review of recent progress in the field of comparative sensory physiology, Prof. O. Lowenstein, president of Section $\Theta$ (Zoology), deals with sense organs classified into three groups, according to the physical nature of the stimuli to which they respond. Electro-magnetic waves (light and radiant heat) are the appropriate stimuli for photo-receptors, mechanical deformation of parts of an animal's body are registered by mechano-receptors and chemoreceptors respond to changes in the chemical makeup of the external and internal 'environment' of the body. Up to fairly recently, sense physiologists were chiefly interested in exploring the range of sensory perception available to various animal types, and in an analysis of the range of functions of the various receptor organs. The focus of interest has now shifted to an analysis of the mode of function of sense organs on the cellular level. We are rapidly reaching a point where the ultimate understanding of the physicochemical processes involved in receptor function would have to be studied on a molecular levol.

The chief topic of Prof. Lowenstein's address with reference to all three fields of receptor function is the question of transformation of the energy reaching the receptor organ in the form of its appropriate stimulus into the electrical energy of the final signal which is conveyed from the sense organ to the central nervous system in the form of propagated all-or-nothing action potentials.

All sense organs are incredibly sensitive. Their sensitivity thresholds lie in most cases near the limits of self-stimulation by molecular agitation. The energy content of stimuli at threshold is therefore minute. One quantum of light is sufficient to set up an excited state in a single visual rod in the retina of the mammalian eye. Such a rod presents a target of two thousand million photo-sensitive molecules of visual pigment to an incident light beam. A dent of half of a thousandth part of a millimetre in the nerve. ending of a tactile receptor and probably one molecule only of a scent are sufficient to set going the processes involved in the sensory perception of the stimulus. It is quite clear that the electrical signals which are generated by these stimuli and which are the carriers of coded information from sense organ to central nervous system have an energy content many powers of ten higher than the stimuli. A process of amplification must therefore be incorporated in the sensory mechanism.

One of the chief problems confronting the sense physiologist of to-day is to find out how an electromagnetic, mechanical or chemical stimulus is transformed into the electrical sensory message. This process of stimulus transduction can only be unravelled by an examination of the ultra-structure of the sensory cell and by a minute analysis of the physicochemical events going on in it.

The electron microscope has in recent years given us a chance to come to grips with this problem. The ultra-structure of visual cells, of sensory cells in the inner ear, of postural and chemo-sensitive receptors in vertebrates and insects, of the receptor cells in the mammalian nose and tongue has been investigated among others. A few tentative first steps have thus been taken in the elucidation of the fundamental receptor mechanism. Refined recording techniques based on the use of micro-electrodes and high-power biological amplifiers are being utilized in the attempt to analyse the mechanism of stimulus transduction. A few first victories in this offensive have been won, and the fact has emerged that great fundamental similarities exist between the cellular processes in all the provinces of sensory function which have been studied by these methods. Exciting new information has also been gained in the field of the study of colour vision, especially in insects. Still great are the gaps in our understanding, and it has to be conceded that a real break-through will not happen until wo are able to push forward the line of attack on to the molecular rather than cellular level of biological organization.

\section{NUBIA : AN AFRICAN FRONTIER REGION}

$7 \mathrm{HE}$ building of President Nasser's High Dam makes Nubia of special interest to geographers.

First there are the physical effects of the Dam. Between November 1964 and November 1975, the Nile waters will rise by stages to some two hundred feet above maximum recorded levels, thus transforming the physical geography of Nubia. When the reservoir is full, a great lake will be formed, 300 miles long and 16 miles wide in places, bisected by the international frontier which divides Egyptian from 